\title{
Exploration on the Training Mode of Computer Professionals Based on the Concept of "New Engineering"
}

\author{
Sun Hongxia, Li Feng, Cao Yanan, Ding Lining \\ Xinglin college, Nantong University
}

Funding source: Research on talent training mode of "new engineering" in local undergraduate colleges and universities (project code: 2019SJA2197)

\begin{abstract}
With the national industrial upgrading and technological innovation in recent years, the construction industry is leading in the direction of informatization, industrialization, intelligence and international integration, which puts forward new requirements for the current traditional mode of computer talent training. The innovation of talent training mode, the improvement of education and teaching, the improvement of education resources and so on have become the urgent problems of new engineering computer professional talent training Absolutely. This paper analyzes the current situation of "new engineering" talent demand and training, points out the shortcomings of the current computer talent training in the teaching concept, teaching mode, teachers and so on, and explores the new engineering computer talent training mode. And take the practice of Henan University School of civil engineering and architecture in the new engineering personnel training as an example, hope to have a certain reference significance for the new engineering computer professional personnel training.
\end{abstract}

Keywords: new engineering; computer; interdisciplinary training; subject integration

DOI: $10.7176 / \mathrm{JEP} / 12-8-03$

Publication date:March $31^{\text {st }} 2021$

\section{Introduction}

For a long time, there is a lack of practical talents and highly skilled talents accumulated in China. In recent years, with the upgrading of industries and technological innovation, the state has formulated "Ai 2", "Internet plus", and " "Made in China 2025" and other major strategies to cultivate engineering talents with solid basic knowledge, strong engineering practice ability, and excellent comprehensive quality are of great practical and strategic significance for the vigorous development of China's new economy characterized by endogenous power of new technology, new industrial mode, new consumption and employment mode, and new finance, as well as for the construction of a socialist manufacturing power and new economy It is an important condition for the development of an innovative country. The high demand of new economy for talents puts forward higher requirements for the cultivation of engineering talents, which is born from the application of new engineering. In 2017, the Ministry of Education launched the "new engineering" development research work. The trilogy of "Fudan consensus", "Tianda action" and "Beijing Guide" gave constructive opinions on the construction concept, route and direction of new engineering, brought new opportunities and new development ideas for the education reform and development of computer major in Colleges and universities, and accelerated the process of realizing China's education power.

As a traditional basic discipline, computer major mainly takes computer composition principle and data structure as the core, and integrates computer science, University Physics, discrete mathematics and other multi disciplines. It has the ability to integrate emerging technologies and the conditions and foundation to carry out the reform and exploration of new engineering talent training mode. Computer major should give full play to the supporting role of basic disciplines and the advantages of interdisciplinary integration, and actively explore the computer education mode to adapt to the development of new engineering. This paper first analyzes the current situation of computer professional training, the existing problems, in order to explore the new engineering talent training program and corresponding measures, to provide reference for the construction of new engineering computer talent training.

\section{2. the traditional training mode of computer specialty can not meet the needs of the new economy}

New engineering talent training, not only to build a solid foundation of professional knowledge system, but also to carry out cross-border training, with "non-traditional" ideas to inspire inspiration, truly cultivate "learning has specialized, multi-disciplinary multi-functional" comprehensive talents. But these goals can not be achieved by the traditional professional training mode. Compared with the characteristics and requirements of new engineering civil engineering talents, there is a big gap between the existing engineering education mode of computer colleges and the new engineering talents training, and the problems are prominent.

(1) Relatively backward curriculum system and solidified teaching mode

The traditional computer professional curriculum and teaching has formed a certain curriculum system, and 
the teaching mode is relatively fixed, which will lead to the talent training seriously lagging behind the industrial structure adjustment, not in line with the social needs. In the process of computer teaching, it is very difficult for students to actively participate in the teaching, which leads to the situation of students' passive acceptance, lack of self exploration and research consciousness, always participate in the teaching under the arrangement of teachers, lack of their own ideas and understanding, and inflexible thinking mode. In addition, students passively absorb a lot of theoretical knowledge from books in class, and are tired of dealing with various examinations and examinations. Their knowledge is only limited to the superficial understanding of books, and they don't know how to further explore, which makes teaching boring. This is mainly because the school does not fully realize the professional development in the cognition of talent training, and there is a certain deviation, so it can not adjust the professional training objectives in time.

\section{(2) The practice teaching is weak and the mode is single}

Practical teaching of computer major occupies a very important position in college education. It is an important part of training applied talents and implementing comprehensive quality education. At present, the practice teaching mode is single, and there is a lack of systematic connection between the practice teaching and the theory teaching. The two aspects are in a "free" state. Students can not effectively apply the theoretical knowledge to engineering practice, and lack the ability to find and solve problems in complex engineering.

\section{(3) Lack of interdisciplinary faculty}

"New engineering" engineering education mode requires teachers to have strong interdisciplinary knowledge expansion, so as to carry out interdisciplinary indoctrination and guidance in teaching. At present, professional teachers mainly carry out learning, teaching and scientific research in their own disciplines, even in several courses within the discipline. It is difficult for teachers' personal knowledge reserve to adapt to the development of new technology and new economy. The construction of interdisciplinary teachers has become an important factor in the construction of interdisciplinary specialty.

(4)There are few opportunities for inter disciplinary interaction

"New engineering" has given birth to new industries and formats characterized by interdisciplinary, as well as new technologies and new economy characterized by cross-border integration. At present, most of the traditional computer major students only study the professional knowledge, only can achieve "one specialty", but can not meet the requirements of "multi specialty and multi ability".

\section{Exploration on the training mode of computer talents in three new engineering courses}

New engineering talents should not only have theoretical basis, learning ability and creative thinking, but also have the spirit of cooperation, family and country feelings and thinking about the community of human destiny. New engineering talents training, not only to build a solid professional knowledge system, but also to carry out crossborder training, technological innovation. In the training path, new engineering talents are very different from the traditional teaching mode. It not only carries out flexible education system, large class enrollment, cross-border training, but also integrates production, learning, research and teaching on the basis of interdisciplinary, builds an innovation platform, and conforms to the trend of the times.

\section{(1) Training plan formulation and training objectives}

New engineering computer talents should have the ability of interdisciplinary and cross-border integration [1], so the development of talent training program for computer specialty should take this as the characteristic to construct the training program for computer specialty with the attribute of new engineering. In order to better determine the training program of computer talents for new engineering, it is necessary to conduct in-depth analysis and Research on interdisciplinary subjects, find out the needs of social talents in a wide range, discuss with teachers and students, and evaluate the software and hardware of the school. According to the previous research basis, combined with the characteristics of the computer specialty of our university, the training program and training objectives of new engineering computer talents are determined.

Combined with the requirements of computer professional certification and the characteristics of new engineering, graduates need to have the following core competitiveness [2]: (1) multi-disciplinary knowledge application ability; (2) complex data processing problem analysis ability; (3) complex system design and development ability; (4) literature research and empirical analysis ability; (5) modern tool use ability; (6) Engineer's social responsibility consciousness; (5) project management ability; (7) Communication skills.

\section{(2) Reconstruction of interdisciplinary curriculum system}

Modern computer is a combination of multi-disciplinary knowledge system integration, showing a trend of highly integrated and cross-border knowledge and technology, involving a wide range of knowledge systems, which not only has the attributes of natural science, but also has the attributes of Humanities and industrial economy [3]. Grasp the interdisciplinary characteristics of "new engineering" and reconstruct the curriculum system of "new engineering".

Taking the computer major as an example, we should not only embody the solid basic knowledge of the major, 
but also require the knowledge structure of interdisciplinary solid foundation: pay attention to the basic knowledge education in the "new engineering" professional education to support the whole computer professional knowledge system; require the basic knowledge of interdisciplinary solid, in order to cultivate interdisciplinary thinking training and discipline integration ability. We can explore the establishment of a large computer specialty integrating computer science, data structure, economic management and other multidisciplinary knowledge; focus on the integration of new industrial technology into the "new engineering" professional education curriculum system, and gradually deepen the explanation and edification through a series of knowledge fusion engineering cases, Guide students to develop their thinking, cultivate their innovative ability, and establish a "private customized" version of "new engineering" suitable for personal development.

Integrate the curriculum system to make the core curriculum system more systematic. Xinglin College of Nantong University is exploring the reconstruction of curriculum system with the concept and requirements of "new engineering". With "computer"+ Taking "software engineering" as an example, the computer professional courses can select higher mathematics, linear algebra, probability theory and mathematical statistics, discrete mathematics, introduction to software engineering, high-level language programming, computer digital logic design as the supporting compulsory subjects; the computer science professional courses can select data structure, operating system, computer composition principle, database principle and application, computing Computer network and assembly language programming are required courses to support computer science. Through the practical system example, through the systematic basic engineering training of software and hardware, the "new engineering" knowledge of subject integration is applied. Through the professional special skill training, students can master the solid basic theory and professional knowledge of computer science, and have the professional ability to engage in it engineering practice as engineers, so as to achieve the ability to carry out software and hardware development projects Through the training of scientific research thinking, we should gradually form the habit of scientific research, hold scientific research and innovation competitions regularly, and stimulate students' initiative innovation ability, as shown in Figure 1.

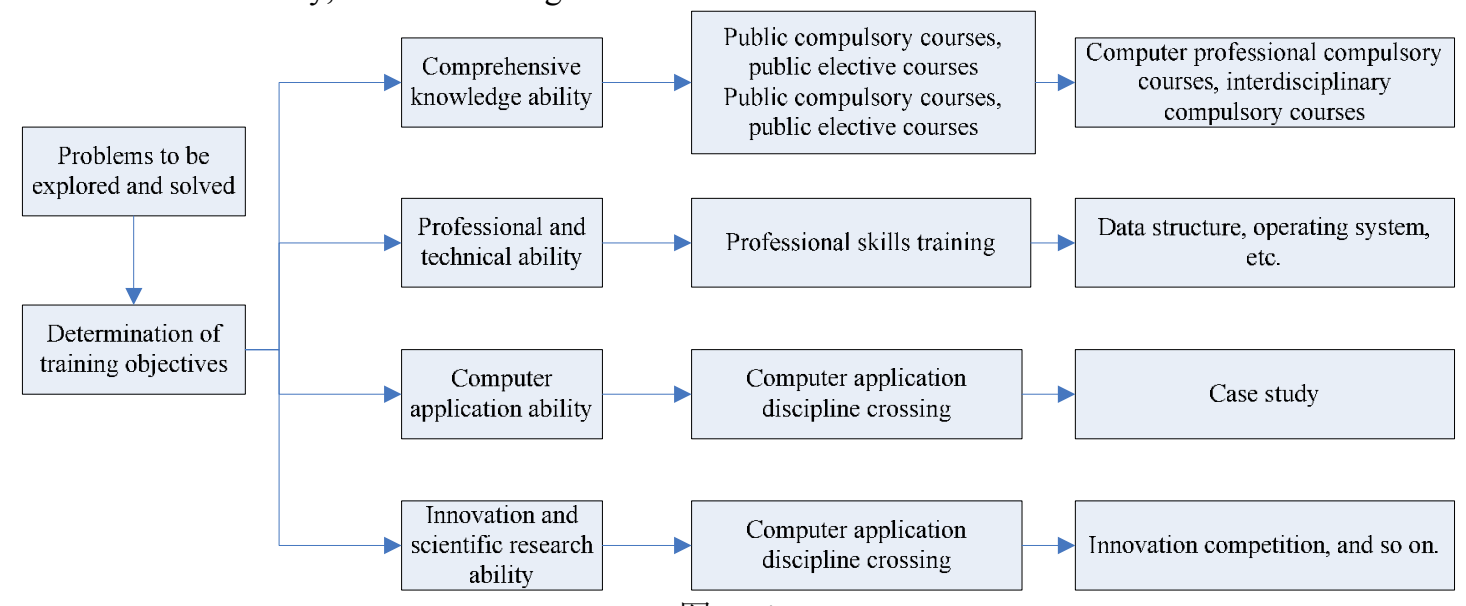

图 1 Figure 1

\section{(3) The construction of teaching staff and teaching resources}

Under the background of new engineering, the cultivation and construction of computer talents is a systematic project, and the first is the construction of teaching staff. The quality of teaching staff directly determines the success or failure of talent training objectives, so it is very important to strengthen the construction of teaching staff. According to the requirements of the new engineering concept, the construction of teaching staff needs to further optimize the structure of professional title, teaching structure and scientific research ability of the teaching staff, so as to build a high-level teaching staff full of vitality and adapt to the cultivation of new engineering talents. The school of civil engineering and architecture of Henan University encourages in-service teachers to often go to enterprises and other colleges and universities for certain learning exercises, constantly send excellent talents as visiting scholars to go abroad for further study, understand the talent needs of modern enterprises, and discuss teaching problems with other university teachers, so as to achieve "targeted" in normal teaching. At the same time, we should pay attention to the introduction of social education resources, and employ engineers with rich design and implementation experience from software development companies, hardware development companies and research companies as part-time teachers to guide students' internship, curriculum design and graduation design, so as to further enrich the whole teaching staff. The integration of disciplines is the necessity of the development of the times. The combination of production, study and research is the essential requirement of engineering education, and is also the necessary quality of teachers and the direction of teaching in the new era. Only by constructing the collaborative training mode of enterprises, research institutions and other multi-agent participation, and the collaborative training mode of industry university research integration of new 
engineering talents, can the construction of teaching resources be continuously strengthened. Teaching is a dynamic process, the latest computer industry trends, emerging technologies and new theories, as well as the industry's latest requirements for personnel training are interspersed in the teaching, gradually optimize and improve the teaching content and curriculum system, and build the curriculum and textbook resources to meet the needs of industry development. In addition, we should promote teachers to incline scientific research tasks to students, guide students to carry out different degrees of scientific research, introduce new progress of discipline research to students, transform scientific research achievements into teaching contents in time, improve curriculum interest, and promote students' all-round development; optimize the school collaborative education mode, and establish a new interdisciplinary institution, Establish a mechanism and system to adapt to the development of new engineering, To provide institutional guarantee for the training of new engineering talents across departments, disciplines, specialties, even schools and platforms; to build a shared collaborative education practice platform integrating education, training, $\mathrm{R} \& \mathrm{D}$ and practice with multi-agent participation, industry university research integration, interdisciplinary and school enterprise cooperation, so as to promote the reform of computer education.

\section{Conclusion}

It is the starting point and foothold of "new engineering" talent training concept to cultivate "multi specialty and multi ability" computer talents with subject integration and certain innovation ability. There is no unified formula for the training of "new engineering" talents, and all colleges and universities are exploring and practicing. In teaching, the purpose and value of subject integration are mainly reflected in solving new problems in the development of new formats and new technologies, and cultivating students' innovation ability. All subject integration serves to solve problems, which is the fundamental orientation of subject integration. In the actual teaching, we should not deliberately graft all kinds of subject knowledge in order to highlight the integration of subjects. There is no distinction between primary and secondary. The integration of subjects is not the more the better, but based on the solution of practical problems. Otherwise, there will be a blind area of "primary or secondary" in teaching, which will make students confused. Only based on the basic knowledge and skills of traditional disciplines, carry out purposeful interdisciplinary training, establish a perfect curriculum system and education system, and build a multi integrated innovation platform, can we really cultivate the interdisciplinary geotechnical engineering talents needed by "new engineering".

\section{Reference}

[1] Zhang Daliang. Change according to the time, start new construction and develop new engineering [J]. China University teaching, 2017 (4): 4-9.

[2] Meng lijiu, Zhao Qi. Concept orientation of new engineering construction and action choice of local engineering colleges [J]. Research on maritime education, 2019,36 (02): 44-49.

[3] Zhong Denghua. Connotation and action of new engineering construction [J]. Research on higher engineering education, 2017 (03): 1-6. 